\title{
Prevalence of ESBL-Producing Klebsiella pneumoniae Isolates in Tertiary Care Hospital
}

\author{
Vemula Sarojamma $^{1}$ and Vadde Ramakrishna ${ }^{2}$ \\ ${ }^{1}$ Department of Microbiology, Government Medical College, Anantapur 515001, India \\ ${ }^{2}$ Department of Biotechnology and Bioinformatics, Yogi Vemana University, Kadapa 516003, India
}

Correspondence should be addressed to Vemula Sarojamma, vemula_saroja@yahoo.co.in

Received 25 August 2011; Accepted 19 October 2011

Academic Editors: A. Netrusov and P. Zunino

Copyright (C) 2011 V. Sarojamma and V. Ramakrishna. This is an open access article distributed under the Creative Commons Attribution License, which permits unrestricted use, distribution, and reproduction in any medium, provided the original work is properly cited.

\begin{abstract}
Extended-spectrum $\beta$ lactamases (ESBLs) continue to be a major challenge in clinical setups world over, conferring resistance to the expanded-spectrum cephalosporins. An attempt was made to study the prevalence of ESBL-producing Klebsiella pneumoniae clinical isolates in a tertiary care hospital in Kurnool. A total of hundred collected isolates of Klebsiella pneumoniae was studied for their susceptibility patterns to various antibiotics and detection of ESBL producers by double disc synergy test (DDST) and phenotypic confirmatory disc diffusion test (PCDDT). Of the 100 isolates tested for their antibiogram, $61 \%$ isolates have shown susceptibility to 3rd-generation cepholosporins and 39\% were resistant. Amoxycillin showed the highest percentage of resistance followed by tetracyclins and cotrimoxazole. Among 39 resistant isolates of Klebsiella pneumoniae, 17 were ESBL producers detected by DDST and PCDDT. ESBL producers were more in the hospital isolates (28\%) compared to community isolates (6\%). Maximum percentage of ESBL producers were noticed from blood sample with $57.14 \%$. In the present study, a large number of isolates were found to be multidrug resistant and ESBL producers. PCDDT was found to be better than DDST in the detection of ESBLs. Continued monitoring of drug resistance is necessary in clinical settings for proper disease management.
\end{abstract}

\section{Introduction}

$\beta$-Lactam antimicrobial agents represent the most common treatment for bacterial infections and continue to be the leading cause of resistance to $\beta$-lactam antibiotics among Gram-negative bacteria worldwide. The persistent exposure of bacterial strains to a multitude of $\beta$-lactams has induced dynamic and continuous production and mutation of $\beta$ lactamases in these bacteria, expanding their activity even against the newly developed $\beta$-lactam antibiotics. These enzymes are known as extended-spectrum $\beta$-lactamases (ESBLs) [1-3]. Treatment of these multiple drug-resistant organisms is a therapeutic challenge. At the level of a wider geographic scale, the incidence of ESBL-producing organisms is difficult to determine due to various reasons, difficulty in detecting ESBL production and inconsistencies in reporting [4]. In recent surveys, a significant increase in the ESBL rate was reported from all parts of the world [5-12].
Klebsiella pneumoniae and Escherichia coli remain the major ESBL-producing organisms isolated worldwide [13] which are recommended to be routinely tested for and reported by the Clinical and Laboratory Standards Institute [14]. Prevalence of ESBLs varies from an institute to another. Previous studies from India and abroad have reported ESBL production varying from 8 to $80 \%$. However, there is paucity scientific information available on antibiotic profile with rate of ESBL production in Klebsiella pneumoniae isolates. Keeping in view the above facts, the present study was undertaken to find the prevalence of ESBL producers among Klebsiella pneumoniae isolates at our institute.

Government General Hospital, Kurnool is a 1200-bedded hospital with a daily outpatient turnover of more than 2000 . It is a tertiary care hospital and a referral centre to the hospitals in the surrounding districts. Klebsiella pneumoniae is one of the commonest organisms associated with the hospital acquired infections. Hence, the present study is attempted to 
evaluate the extent of prevalence of ESBL-producing strains of Klebsiella pneuoniae in the hospital and community along with antibiotic resistance profile.

\section{Materials and Methods}

This prospective study was conducted in the Department of Microbiology at Kurnool Medical College, Kurnool, Andhra Pradesh. A total of 100 isolates were obtained from clinical samples from January to October 2008. Among 100 isolates, 50 were from out patients and remaining 50 from in patients admitted into Government General Hospital in units like medical, surgical, orthopedic, burns, pediatric, neonatal intensive care units, and acute medical care units.

\section{Processing of Samples}

All samples were inoculated on Mac Conkey's and Blood agar, incubated at $37^{\circ} \mathrm{C}$ for overnight, and colonies were processed. In case of blood sample, blood was incubated at $37^{\circ} \mathrm{C}$ overnight in Brain Heart infusion broth. A drop of Brain Heart Infusion broth was inoculated on Mac Conkey agar and Blood agar and incubated at $37^{\circ} \mathrm{C}$ for overnight. If colonies were not seen even after 7 days, the blood sample was reported as negative. Colonies in any of these 7 days, were subcultured. Klebsiella pneumoniae isolates that were obtained as a pure and predominant growth from the clinical specimens were only considered for the present study. The organisms were identified based on colony morphology and biochemical reactions [15].

\section{Antimicrobial Susceptibility Testing}

Routine disc diffusion susceptibility testing was performed by modified KirbyBauer's disc diffusion method [16]. Various antimicrobial discs were used which include antimicrobials for screening of ESBL Klebsiella species: cefotaxime $-30 \mu \mathrm{g}$; ceftazidime $-30 \mu \mathrm{g}$; ceftriaxone $-30 \mu \mathrm{g}$; amikacin $-10 \mu \mathrm{g}$; amoxycillin $-20 \mu \mathrm{g}$; gentamycin $-10 \mu \mathrm{g}$; tetracycline $-30 \mu \mathrm{g}$; imipenem $-30 \mu \mathrm{g}$; ciprofloxacin $-5 \mu \mathrm{g}$; aztreonam-30 $\mu$ g; cotrimoxazole $-1.25 / 23.75 \mu \mathrm{g}$. The results were interpreted as per the National Committee for Clinical Laboratory Standards (NCCLS) recommendations [17]. Klebsiella pneumoniae ATCC 700603 (ESBL positive) strain was used as control throughout the study. Isolates with resistance or with decreased susceptibility (intermediate by NCCLS criteria) to any of the 3GC were selected for further study.

\section{Screening of ESBL-Producing Strains for Klebsiella pneumoniae}

Clinical and Laboratory Standards Institute [14] has developed screening tests for identifying the ESBL-producing Klebsiellla species. According to CLSI guidelines, strains showing zone of inhibition of $\leq 22 \mathrm{~mm}$ for ceftazidime, $\leq 27 \mathrm{~mm}$ for cefotaxime, and $\leq 25 \mathrm{~mm}$ for ceftriaxone were selected for conformational tests of ESBL.

\subsection{ESBL Confirmatory Tests}

5.1.1. Double Disc Synergy Test (DDST) [18]. The isolated colonies were inoculated in peptone water at $37^{\circ} \mathrm{C}$ for $2-6 \mathrm{~h}$. The turbidity was adjusted to $0.5 \mathrm{Mc}$ Farlands standard and lawn culture was made on Mueller-Hinton agar using sterile swab. Augmentin disc $(20 / 10 \mu \mathrm{g})$ was placed in the centre of plate. Both side of Augmentin disc, a disc of cefotaxime $(30 \mu \mathrm{g})$ and ceftazidime $(30 \mu \mathrm{g})$, were placed with centre to centre distance of $15 \mathrm{~mm}$ to centrally placed disc. The plate was incubated at $37^{\circ} \mathrm{C}$ overnight. ESBL production was interpretated as the $3^{r d}$-generation cephalosporin disc, inhibition was increased towards the Augmentin disc or if neither discs were inhibitory alone but bacterial growth was inhibited where the two antibiotics were diffused together.

5.1.2. Phenotypic Confirmatory Disc Diffusion Test (PCDDT) for ESBL [17]. ESBL production was confirmed among po -tential ESBL-producing isolates by phenotypic tests. Lawn culture of the organism was made and $3^{r d}$-generation cephalosporins ceftazidime $(30 \mu \mathrm{g})$ disc and ceftazidime + clavulinic acid $(30 \mu \mathrm{g}+10 \mu \mathrm{g})$ disc was placed with $25 \mathrm{~mm}$ apart. An increase of $\geq 5 \mathrm{~mm}$ in zone of inhibition for ceftazidime + clavulinic acid compared to ceftazidime was confirmed as ESBL producers.

\section{Results}

A significant difference in resistant and susceptibility pattern was observed with 3rd-generation cepolosporins between hospital and community strains. An antibiogram of the isolates was presented in (Table 1). Of the 100 isolates of Klebsiella pneumoniae tested for their antibiogram, $61 \%$ isolates have shown susceptibility to 3rd-generation cepholosporins and 39\% were resistant. Amoxycillin showed the highest percentage of resistance $(86 \%$ in hospital and $76 \%$ in community) followed by tetracyclins and cotrimoxazole. Similarly, a highest percentage susceptibility to imipenam (84\% hospital, $96 \%$ community) followed by ceftriaxone, cefaperazone + sulbactum were noticed. In the case of aminoglycosides, amikacin showed higher percentage of susceptibility (56\% in hospital and $78 \%$ in community) compared to gentamycin ( $40 \%$ in hospital and $62 \%$ in community).

Of the 100 clinical isolates of Klebsiella pneumoniae, 39 were screened according to CLSI guidelines and selected for conformational tests of ESBL. The two techniques were used in the present study to confirm ESBL-producing Klebsiella pneumoniae, namely, DDST and PCDDT and confirmed $28 \%$ hospital and 6\% community isolates were the ESBL producers. The results (Table 2) showing that of the $17 \mathrm{Kleb}$ siella pneumoniae isolates, 15 isolates were positive by DDST $(88.23 \%)$, however, PCDDT shown that all 17 were positive (100\%). Among 17 strains of ESBL-producing Klebsiella pneumoniae, 3 isolates are resistant to one of the 3GCs, 5 are against the 2 of the $3 \mathrm{GCs}$, and 9 are resistant to all the $3 \mathrm{GCs}$. DDST fail to detect ESBL in 2 isolates which showed ESBL production by PCDDT. There is no instance of a DDSTpositive and PCDDT-negative ESBL producers. This implies that PCDDT is more sensitive in detecting ESBL production 
TABLE 1: Antibiogram of clinical isolates of Klebsiella pneumoniae.

\begin{tabular}{|c|c|c|c|c|c|c|c|c|c|}
\hline \multirow{3}{*}{ S. no. } & \multirow{3}{*}{$\begin{array}{l}\text { Name of } \\
\text { antibiotic }\end{array}$} & \multicolumn{4}{|c|}{ Hospital isolates } & \multicolumn{4}{|c|}{ Community isolates } \\
\hline & & \multicolumn{2}{|c|}{ Susceptibility } & \multicolumn{2}{|c|}{ Resistant } & \multicolumn{2}{|c|}{ Susceptibility } & \multicolumn{2}{|c|}{ Resistant } \\
\hline & & No. of isolates & Percentage & No. of isolates & Percentage & No. of isolates & Percentage & No. of isolates & Percentage \\
\hline (1) & Amikacin & 28 & $56 \%$ & 22 & $44 \%$ & 39 & $78 \%$ & 11 & $22 \%$ \\
\hline (2) & Gentamycin & 20 & $40 \%$ & 30 & $60 \%$ & 23 & $62 \%$ & 27 & $38 \%$ \\
\hline (3) & Ciprofloxacin & 14 & $28 \%$ & 36 & $72 \%$ & 19 & $38 \%$ & 31 & $62 \%$ \\
\hline (4) & Amoxycillin & 7 & $14 \%$ & 43 & $86 \%$ & 12 & $24 \%$ & 38 & $76 \%$ \\
\hline (5) & Ceftazidime & 22 & $44 \%$ & 28 & $56 \%$ & 40 & $80 \%$ & 10 & $20 \%$ \\
\hline (6) & Ceftriaxone & 28 & $56 \%$ & 22 & $44 \%$ & 42 & $84 \%$ & 8 & $16 \%$ \\
\hline (7) & Cefotaxime & 26 & $52 \%$ & 24 & $48 \%$ & 39 & $78 \%$ & 11 & $22 \%$ \\
\hline (8) & Cotrimoxazole & 10 & $20 \%$ & 40 & $80 \%$ & 13 & $26 \%$ & 37 & $74 \%$ \\
\hline (9) & Imipenem & 42 & $84 \%$ & 8 & $16 \%$ & 48 & $96 \%$ & 2 & $9 \%$ \\
\hline (10) & Aztreonam & 15 & $30 \%$ & 35 & $70 \%$ & 14 & $28 \%$ & 36 & $72 \%$ \\
\hline (11) & $\begin{array}{l}\text { Cefaperazone } \\
+ \text { Sulbactum }\end{array}$ & 30 & $62 \%$ & 20 & $38 \%$ & 40 & $82 \%$ & 10 & $18 \%$ \\
\hline (12) & Tetracyclin & 4 & $8 \%$ & 42 & $84 \%$ & 12 & $24 \%$ & 38 & $76 \%$ \\
\hline
\end{tabular}

TABLE 2: ESBL pattern of Klebsiella pneumoniae isolated from various clinical samples.

\begin{tabular}{|c|c|c|c|c|c|c|c|c|}
\hline \multirow[t]{2}{*}{$\begin{array}{l}\text { No. of Klebsiella } \\
\text { pneumoniae } \\
\text { isolates }\end{array}$} & \multirow[t]{2}{*}{$\begin{array}{l}\text { Hospital } \\
\text { isolates }\end{array}$} & \multirow[t]{2}{*}{$\begin{array}{l}\text { Community } \\
\text { isolates }\end{array}$} & \multicolumn{2}{|c|}{$\begin{array}{l}\text { No. of screened and } \\
\text { selected isolates for } \\
\text { ESBL confirmatory tests } \\
\text { (39) }\end{array}$} & \multicolumn{2}{|c|}{$\begin{array}{l}\text { No. of ESBL confirmed } \\
\qquad(17)\end{array}$} & \multicolumn{2}{|c|}{ No. of ESBL confirmed by } \\
\hline & & & Hospital & Community & Hospital & Community & DDST & PCDDT \\
\hline 100 & 50 & 50 & 30 & 9 & $14(28 \%)$ & $3(6 \%)$ & $15(88 \%)$ & $17(100 \%)$ \\
\hline
\end{tabular}

than DDST. Among 17 confirmed ESBL producers, the Hospital isolates are the major ESBL producers.

\section{Discussion}

In India, high prevalence of ESBL-producing Klebsiella pneumoniae strains has been reported by various groups [19-22]. In the present study, we noticed the prevalence of ESBL-producing Klebsiella is $17 \%$. The percentage of ESBLproducing organisms ranged from $4 \%$ to $83 \%$ in India. The percentage is lowest in Maharastra reported by Rodrigues et al. [21] that the $4(8.5 \%)$ positive ESBL producers among 47 Klebsiella pneumoniae isolates. Probably, it reflects emerging phase of ESBL production which by now would have increased in the same place if a similar study is conducted in the present time. This is understandable as the prevalence of ESBL producers in any hospital depends upon various factors like antibiotic policy, the carriage rate among the hospital personal, and the type of disinfection used especially in ICU [23]. These have not been extensive studies available in India. These strains are often undetectable by routine susceptibility testing methods. It can be presumed that ESBL-producing strains are more prevalent than currently recognized.

In the present study, among the 50 nosocomial isolates, 30 isolates were shown resistance to $3 \mathrm{GCs}(60 \%)$. Of these 30 isolates, the 14 showed ESBL production (28\%). However, the percentage of ESBL producers in community isolates tested was only $6 \%$. The present results were correlated with that of Shukla et al. [24] reported that 32\% of Klebsiella pneumoniae from 120 samples of tertiary care hospital. Some of the authors feel that ESBL screening is not likely to affect the patient outcome and hence neither necessary nor cost, effective for the laboratories. They also observed good clinical outcome with cephalosporins for treatment of infections with ESBL-producing organisms. This is an argument against routine screening for ESBL production $[25,26]$.

In the present study, the highest percentage of ESBL was reported from blood followed by stool, sputum, urine, and pus samples (Table 3). A total number of 7 blood samples were processed from septicemic patients and reported $57.14 \%$ samples to have ESBL strains of Klebsiella pneumoniae. Similar reports have been recorded in the recent past by Guptha et al. [27]: from Chandigarh isolated 9 ESBLproducing Klebsiella pneumoniae from 13 blood samples in septicemia patients with the percentage of $69.2 \%$. Another study by Ananthan and Subha [23] has shown 92.85\% ESBL producers from septicemia in a study of 14 cases. The prevalence of ESBL in septicemia individual has great importance as most of ESBL Klebsilla pneumoniae are multidrug resistant. There will be great limitation over the choice of drug for treating the septicemia patients. There is $50 \%$ incidence of ESBL production in isolates from stool samples. Only two Klebsiella pneumoniae isolates could be obtained from stool samples of admitted patients. Here the sample 
TABLE 3: Sa mple wise distribution of ESBL producing Klebsiella penumoniae.

\begin{tabular}{lcccc}
\hline S. no. & Sample & $\begin{array}{c}\text { No. Klebsiella } \\
\text { pneumoniae } \\
\text { isolates }\end{array}$ & $\begin{array}{c}\text { ESBL producing K. pneumoniae } \\
\text { No. of } \\
\text { isolates }\end{array}$ & Percentage \\
\hline 1 & Sputum & 42 & 8 & $19.04 \%$ \\
2 & Urine & 23 & 3 & $13.04 \%$ \\
3 & Pus & 16 & 2 & $12.05 \%$ \\
4 & Blood & 7 & 4 & $57.14 \%$ \\
5 & Stool & 2 & 1 & $50 \%$ \\
\hline
\end{tabular}

number is quite less and hence percentage does not depict the exact one. However, the gastrointestinal carriage and asymptomatic colonization with ESBL producers among inpatients has been well documented [28].

A significant number of ESBL-positive cases are recorded from sputum samples. Out of 42 sputum samples 8 were ESBL positive with the percentage of $19.04 \%$. This may be because many of the sputum samples are taken from ICU wards. In the present study, 28\% ESBLs are reported from patients admitted into hospital. A study conducted in Aligarh tertiary care hospital has also reported 30.18\% ESBL Klebsiella pneumonaie from clinical samples [27]. A study conducted by Ananthan and Subha [23] from Chennai reported 23.6\% of ESBL Klebsiella pneumoniae from clinical isolates. In other studies, Menon et al. [29] from Chennai and Supriya et al. [30] from Nagpur have also reported the prevalence of ESBL producing Klebsiella pneumoniae were $21.2 \%$ and $25.65 \%$, respectively.

In recent years, a significant increase in ESBL-producing Klebsiella spp. was also reported from USA 4.2-44\% [3032] Canada 4.9\% [33], Spain 20.8\% [9], Taiwan 28.4\% [10], Turkey 78.6\% [11], Algeria 20\% [12], and China 51\% [34]. Focusing on the epidemiology in Europe, there are considerable geographical differences in the occurrence of ESBLs. A recent large survey of 1610 Escherichia coli and $785 \mathrm{~K}$. pneumoniae isolates from 31 centers in 10 European countries found that the prevalence of ESBL in these organisms ranged from as low as 1.5\% in Germany to as high as $39-47 \%$ in Russia, Poland, and Turkey [35].

Looking at the overall trend of ESBL Klebsiella pneumoniae is on the rise and variable. This could partly be irrational use of cephalosporins at some institutions and more number of blood samples was processed. The actual magnitude of problem posed by ESBL producers is not known as routine susceptibility testing fails to detect all ESBL producers. The two techniques used in the present study to confirm ESBL production are, namely, DDST and PCDDT. DDST fail to detect ESBL in 2 isolates which showed ESBL production by PCDDT. There is no instance of a DDST-positive and PCDDT-negative ESBL producers. This implies that PCDDT is more sensitive in detecting ESBL production than DDST. Looking at all other authors and in the present study, it is confirmed that PCDDT is more sensitive than DDST for detection of ESBLs [36-38].
In conclusion, our study highlights the prevalence of ESBL-producing Klebsiella pneumoniae in Government General Hospital, Kurnool, having a significant percentage. Routine detection of ESBL-producing microorganisms is required to be done by each laboratory by the standard detection methods so as to control the spread of these infections and also to institute proper therapeutic strategies. For the detection, the phenotypic confirmatory disc diffusion test is simple, sensitive, and costeffective. However there is a need to emphasize on the rational use of antimicrobials and strictly adhere to the concept of "reserve drugs" to minimize the misuse of available antimicrobials. In addition, regular antimicrobial susceptibility surveillance is essential.

\section{Conflict of Interests}

The authors declare that no conflict of interests.

\section{References}

[1] D. M. Livermore, "Bacterial resistance: origins, epidemiology, and impact," Clinical Infectious Diseases, vol. 36, supplement 1, pp. S11-S23, 2003.

[2] D. L. Paterson and R. A. Bonomo, "Extended-spectrum $\beta$ lactamases: a clinical update," Clinical Microbiology Reviews, vol. 18, no. 4, pp. 657-686, 2005.

[3] J. D. Pitout and K. B. Laupland, "Extended-spectrum $\beta$ lactamase-producing Enterobacteriaceae: an emerging publichealth concern," The Lancet Infectious Diseases, vol. 8, no. 3, pp. 159-166, 2008.

[4] C. D. Steward, D. Wallace, S. K. Hubert et al., "Ability of laboratories to detect emerging antimicrobial resistance in nosocomial pathogens: a survey of Project ICARE laboratories," Diagnostic Microbiology and Infectious Disease, vol. 38, no. 1, pp. 59-67, 2000.

[5] V. Gupta, "An update on newer $\beta$-lactamases," Indian Journal of Medical Research, vol. 126, no. 5, pp. 417-427, 2007.

[6] D. M. Livermore, R. Canton, M. Gniadkowski et al., "CTX-M: changing the face of ESBLs in Europe," Journal of Antimicrobial Chemotherapy, vol. 59, no. 2, pp. 165-174, 2007.

[7] E. Stürenburg and D. Mack, "Extended-spectrum $\beta$ lactamases: implications for the clinical microbiology laboratory, therapy, and infection control," Journal of Infection, vol. 47, no. 4, pp. 273-295, 2003.

[8] F. Perez, A. Endimiani, K. M. Hujer, and R. A. Bonomo, "The continuing challenge of ESBLs," Current Opinion in Pharmacology, vol. 7, no. 5, pp. 459-469, 2007.

[9] E. D.V. Romero, T. P. Padilla, A. H. Hernández et al., "Prevalence of clinical isolates of Escherichia coli and Klebsiella spp. producing multiple extended-spectrum $\beta$-lactamases," Diagnostic Microbiology and Infectious Disease, vol. 59, no. 4, pp. 433-437, 2007.

[10] K. C. Kuo, Y. H. Shen, and K. P. Hwang, "Clinical implications and risk factors of extended-spectrum beta-lactamaseproducing Klebsiella pneumoniae infection in children: a casecontrol retrospective study in a medical center in southern Taiwan," Journal of Microbiology, Immunology and Infection, vol. 40, no. 3, pp. 248-254, 2007.

[11] S. Hoşoğlu, S. Gundes, F. Kolayli et al., "Extended-spectrum beta-lactamases in ceftazidime-resistant Escherichia coli and Klebsiella pneumoniae isolates in Turkish hospitals," Indian 
Journal of Medical Microbiology, vol. 25, no. 4, pp. 346-350, 2007.

[12] Y. Messai, H. Iabadene, T. Benhassine et al., "Prevalence and characterization of extended-spectrum $\beta$-lactamases in Klebsiella pneumoniae in Algiers hospitals (Algeria)," Pathologie Biologie, vol. 56, no. 5, pp. 319-325, 2008.

[13] G. A. Jacoby and L. S. Munoz-Price, "The new $\beta$-lactamases," The New England Journal of Medicine, vol. 352, no. 4, pp. 380 391, 2005.

[14] Clinical Laboratory Standards Institute CLSI, "Performance standards for antimicrobial susceptibility testing," in Proceedings of the 16th International Supplement (M100-S16), National Committee for Clinical Laboratory Standards, Wayne, Pa, USA, 2006.

[15] W. Washington Jr., A. Stephan, J. William et al., Eds., Koneman's Color Atlas and Text book of Diagnostic Microbiology, Lipponcott Williams \& Wilkins, 6th edition, 2006.

[16] A. W. Bauer, H. Truck, and J. C. Sherries, "Antibiotic Susceptibility testing by standardized single disc method," American Journal of Clinical Pathology, vol. 45, pp. 493-496, 1990.

[17] National Committee for Clinical Laboratory Standards NCCLS, Methods for Dilution Antimicrobial Susceptibility Tests for Bacteria that Grow Aerobically, Approved Standard M7-A5 and informational Supplement M100-S10, National Committee for Clinical Laboratory Standards, Wayne, Pa, USA, 2000.

[18] V. Jarlier, M. H. Nicolas, G. Fournier, and A. Philippon, "Extended broad-spectrum beta-lactamases conferring transferable resistance to newer beta-lactam agents in Enterobacteriaceae: hospital prevalence and susceptibility patterns," Reviews of Infectious Diseases, vol. 10, no. 4, pp. 867-878, 1988.

[19] J. B. Hansotia, V. Agarwal, A. A. Pathak, and A. M. Saoji, "Extended spectrum $\beta$-lactamase mediated resistance to third generation cephalosporins in Klebsiella pneumoniae in Nagpur, central India," Indian Journal of Medical Research, vol. 105, pp. 158-161, 1997.

[20] V. Manchanda, N. P. Singh, R. Goyal, A. Kumar, and S. S. Thukral, "Phenotypic characteristics of clinical isolates of Klebsiella pneumoniae \& evaluation of available phenotypic techniques for detection of extended spectrum betalactamases," Indian Journal of Medical Research, vol. 122, no. 4, pp. 330-337, 2005.

[21] C. Rodrigues, P. Joshi, S. H. Jani, M. Alphonse, R. Radhakrishnan, and A. Mehta, "Detection of $\beta$-lactamases in nosocomial gram negative clinical isolates," Indian Journal of Medical Microbiology, vol. 22, no. 4, pp. 247-250, 2004.

[22] P. Lal, A. Kapil, B. K. Das, and S. Sood, "Occurrence of TEM \& SHV gene in extended spectrum $\beta$-lactamases (ESBLs) producing Klebsiella sp. isolated from a tertiary care hospital," Indian Journal of Medical Research, vol. 125, no. 2, pp. 173$178,2007$.

[23] S. Ananthan and A. Subha, "Cefoxitin resistance mediated by loss of a porin in clinical strains of Klebsiella pneumoniae and Escherichia coli," Indian Journal of Medical Microbiology, vol. 23, no. 1, pp. 20-23, 2005.

[24] I. Shukla, R. Tiwari, and M. Agrawal, "Prevalence of extended spectrum $\beta$-lactamasee producing Klebsiella pneumoniae in a tertiary care hospital," Indian Journal of Medical Microbiology, vol. 22, no. 2, pp. 87-91, 2004.

[25] C. L. Emery and L. A. Weymouth, "Detection and clinical significance of extended-spectrum $\beta$-lactamases in a tertiarycare medical center," Journal of Clinical Microbiology, vol. 35, no. 8, pp. 2061-2067, 1997.
[26] S. Kevin, S. Paul, X. Xiaqqin et al., "Extended spectrum beta lactamase producing Klebsiella pneumoniae strain casing nosocomial outbreaks of infection in the United Kingdom," Journal of Clinical Microbiology, vol. 36, pp. 3105-3110, 1995.

[27] V. Gupta, N. Singla, and J. Chander, "Detection of ESBLs using third and fourth generation cephalosporins in double disc synergy test," Indian Journal of Medical Research, vol. 126, no. 5, pp. 486-487, 2007.

[28] J. C. Lucet, D. Decré, A. Fichelle et al., "Control of a prolonged outbreak of extended-spectrum $\beta$-lactamase- producing Enterobacteriaceae in a university hospital," Clinical Infectious Diseases, vol. 29, no. 6, pp. 1411-1418, 1999.

[29] S. T. Supriya, V. J. Suresh, A. Sarfraz, and H. Umesh, "Evaluation of extended spectrum beta lactamase in urinary isolates," Indian Journal of Medical Research, vol. 120, no. 6, pp. 553-556, 2004.

[30] G. Saurina, J. M. Quale, V. M. Manikal, E. Oydna, and D. Landman, "Antimicrobial resistance in Enterobacteriaceae in Brooklyn, NY: epidemiology and relation to antibiotic usage patterns," Journal of Antimicrobial Chemotherapy, vol. 45, no. 6, pp. 895-898, 2000.

[31] D. Mathai, M. T. Lewis, K. C. Kugler, M. A. Pfaller, and R. N. Jones, "Antibacterial activity of 41 antimicrobials tested against over 2773 bacterial isolates from hospitalized patients with pneumonia: I-results from the SENTRY antimicrobial surveillance program (North America, 1998)," Diagnostic Microbiology and Infectious Disease, vol. 39, no. 2, pp. 105-116, 2001.

[32] P. L. Winokur, R. Canton, J. M. Casellas, and N. Legakis, "Variations in the prevalence of strains expressing an extendedspectrum $\beta$-lactamase phenotype and characterization of isolates from Europe, the Americas, and the Western Pacific region," Clinical Infectious Diseases, vol. 32, supplement 10, pp. S94-S103, 2001.

[33] L. Cordero, R. Rau, D. Taylor, and L. W. Ayers, "Enteric gramnegative bacilli bloodstream infections: 17 Years' experience in a neonatal intensive care unit," American Journal of Infection Control, vol. 32, no. 4, pp. 189-195, 2004.

[34] Z. Xiong, D. Zhu, Y. Zhang, and F. Wang, "Extended-spectrum beta-lactamase in Klebsiella pneumoniae and Escherichia coli isolates," Zhonghua Yi Xue Za Zhi, vol. 82, no. 21, pp. 14761479, 2002.

[35] H. Goossens, "MYSTIC program: summary of European data from 1997 to 2000," Diagnostic Microbiology and Infectious Disease, vol. 41, no. 4, pp. 183-189, 2001.

[36] S. Singhal, T. Mathur, S. Khan et al., "Evaluation of methods for Amp C $\beta$-lactamase in gram negative clinical isolates from tertiary care hospitals," Indian Journal of Medical Microbiology, vol. 23, no. 2, pp. 120-124, 2005.

[37] C. M. C. Lalitha, "Vellore Manual on antimicrobial susceptibility testing," 2005.

[38] V. Manchanda and N. P. Singh, "Occurrence and detection of Amp C $\beta$-lactamases among Gram-negative clinical isolates using a modified tree-dimensional test at Guru Tegh Bahadur hospital, Delhi, India," Journal of Antimicrobial Chemotherapy, vol. 51, no. 2, pp. 415-418, 2003. 

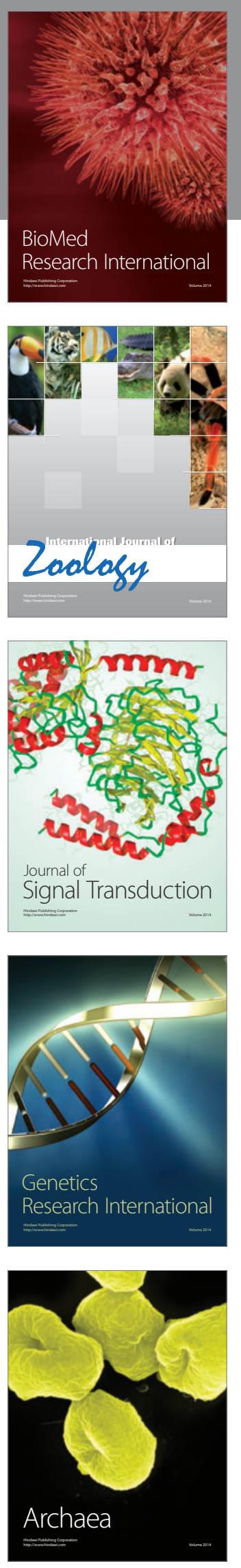
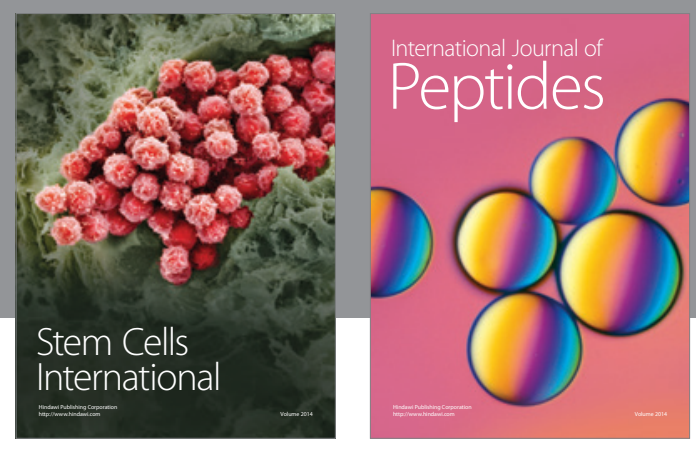

Submit your manuscripts at

http://www.hindawi.com
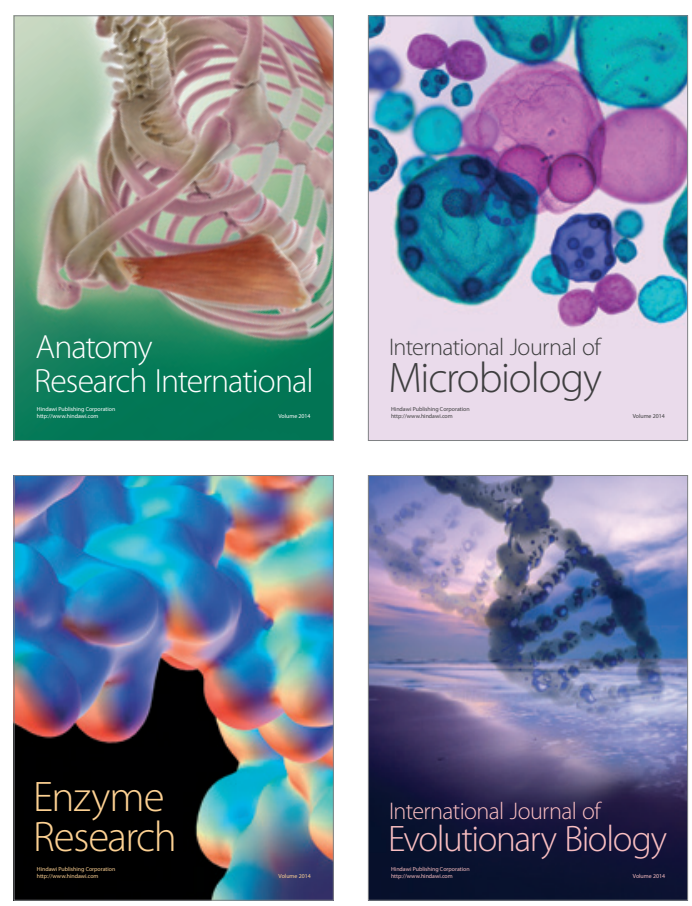
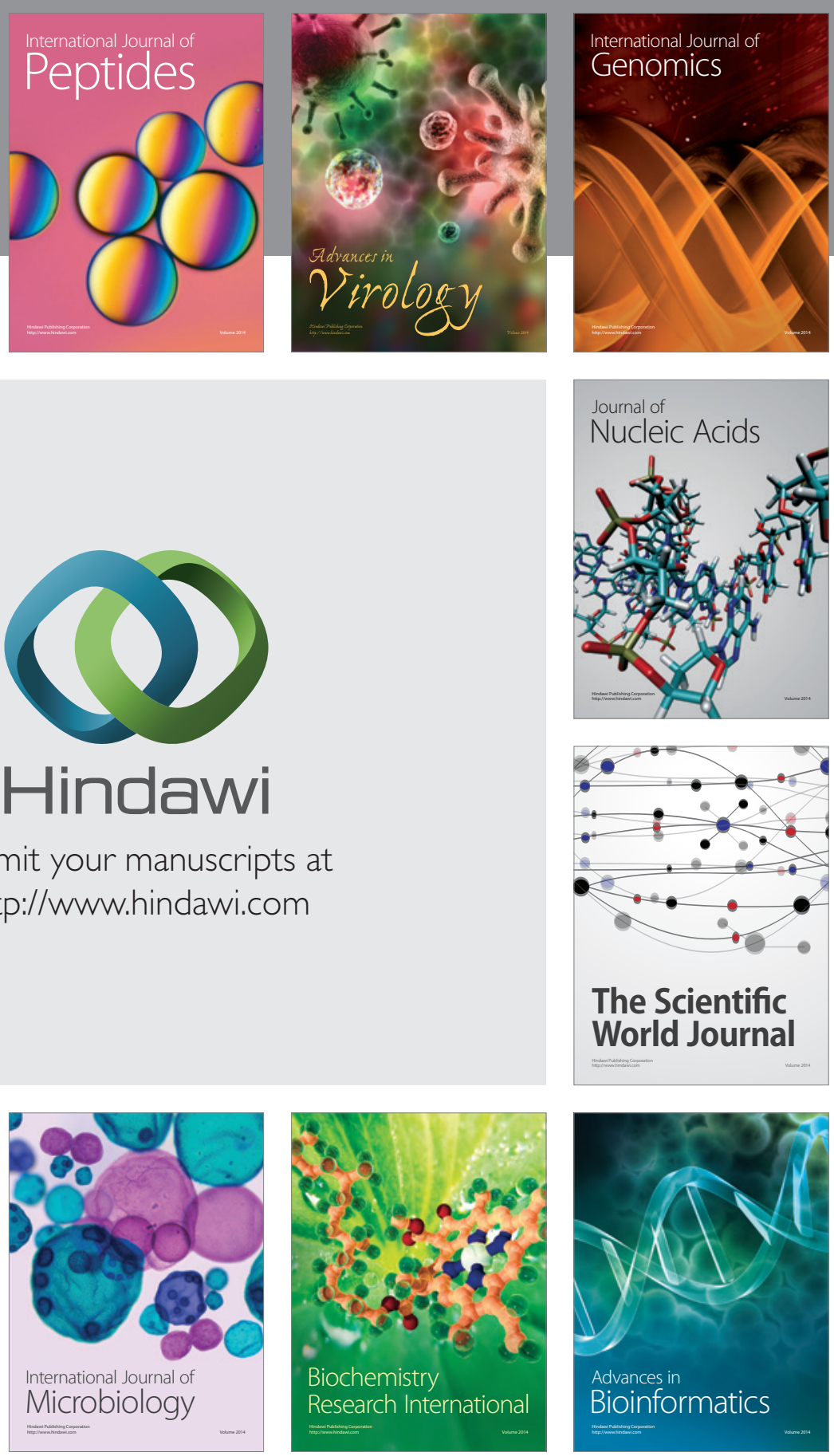

The Scientific World Journal
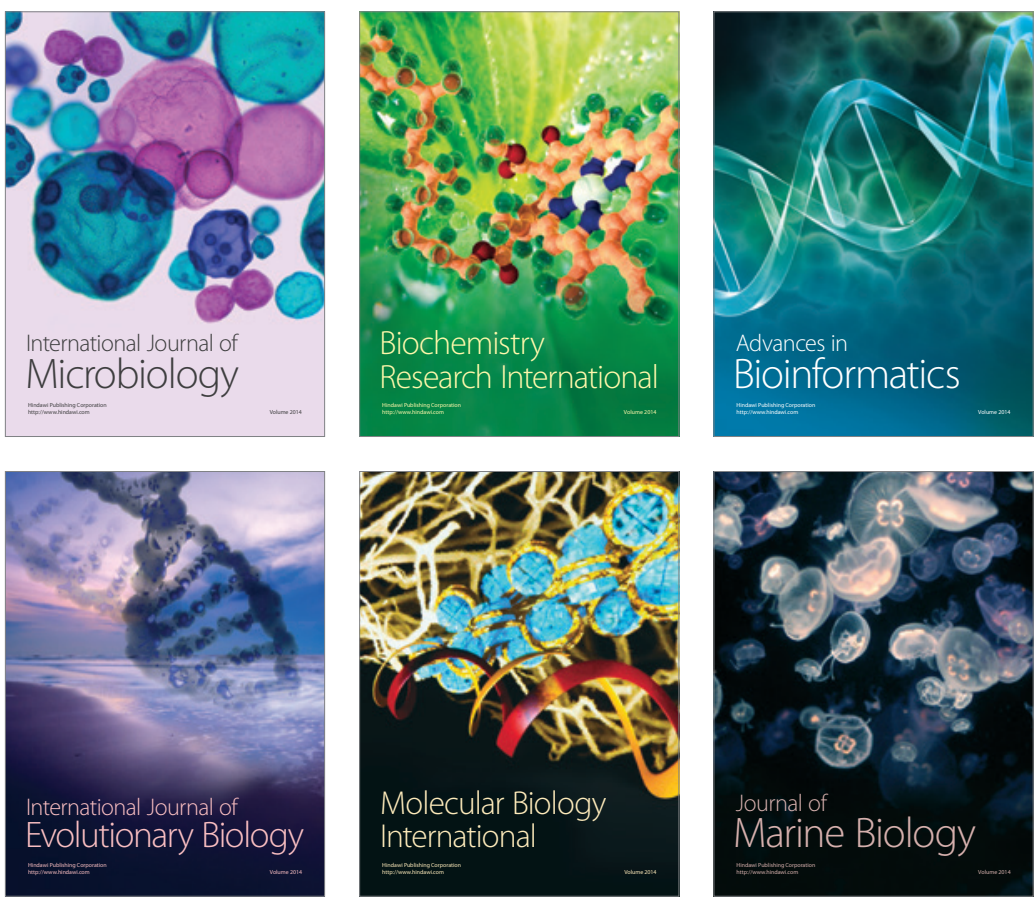